International Journal of Experimental Research and Review (IJERR)

CCopyright by International Academic Publishing House (IAPH), www.iaph.in

ISSN: 2455-4855 (Online)

Review Article

Received: $11^{\text {th }}$ August, 2021; Accepted: $16^{\text {th }}$ November, 2021; Published: $30^{\text {th }}$ December, 2021

DOI: https://doi.org/10.52756/ijerr.2021.v26.008

\title{
Luminescent metal-organic frameworks
}

\author{
Sulagna Biswas ${ }^{1}$, Debabrata Singha ${ }^{2}$ and Nilasish Pal $^{1 *}$ \\ ${ }^{1}$ Department of Chemistry, Seth Anandram Jaipuria College, Kolkata-700005, West \\ Bengal, India; ${ }^{2}$ Department of Chemistry, Visva-Bharati University, Santiniketan, \\ Birbhum-731235, West Bengal, India
}

E-mail/ Orcid id: SB, sulagnabiswas9073@gmail.com, https://orcid.org/0000-0003-3898-938X;

DS, singhadebabrata07@gmail.com,https://orcid.org/0000-0001-8958-2016;

NP, nilasishpal@gmail.com, https://orcid.org/0000-0002-7206-5407

*Corresponding Author : nilasishpal@gmail.com

\begin{abstract}
Metal-organic frameworks (MOFs) show a wide range of luminescent behaviours. In this review, there is a brief discussion on the origins of MOF luminosity due to various type of linkers and their special arrangement in MOFs, the structure and synthesis of the multiple kinds of linker-based luminescent MOFs. Finally, luminescent MOFs as the chemical sensor has been discussed. This article will be helpful for researchers and synthetic chemists attempting for designing luminescent MOFs and their application as a chemical sensor.
\end{abstract}

Keywords: Chemical sensor, Luminescence, Metal-organic frameworks (MOFs).

\section{Introduction}

Metal-organic frameworks (MOFs) have attracted attention for some time. This topic has become one of the most profoundly and extensively pursued areas in research and development. MOFs are often called supra-moelcular solids (Huang et al., 2015), comprised of organic ligands and a metal ion within a porous structure (Rowsell et al., 2004). These solids are highly crystalline. A fascinating property of MOFs is luminescent property. A few reviews on the emissive property of MOFs have been published. The word "luminescent" comprise a large range of observed emissivity properties (including fluorescence, phosphorescence and scintillation) of metal-organic frameworks. This review article focuses on linker-based luminescence, including ligand-localized emission, metal-to-ligand charge transfer (MLCT), and ligand-to-metal charge transfer (LMCT).

While MOFs are a class of supramolecular coordination complexes, the permanent porosity (Tachikawa et al., 2008) in these materials leads to luminescence features by adsorbing guest molecules to luminescent centers. The guest molecules may affect emission properties. Due to the structural flexibility and emissive properties (Cahill et al., 
2007), MOFs could be used for molecular detection (Doty et al., 2009; Hu et al., 2014; Janiak, 2003; Lill et al., 2004).

\section{Concepts relating to luminescence}

Light is frequently produced due to the absorption of energy, which is referred to as luminescence. Most of the time, photons are the source of excitation energy, although it may also be created by an electric field or by ionising radiation. In luminescence, the characteristics of the ground state and lowest-lying electronic states of the metal element and the linker play an important influence in light emission. Several contemporary textbooks are available that cover a variety of themes related to luminescence. Therefore, a succinct summary is presented in this section.

There are two fundamental forms of luminescence (Limpouchová et al., 2016):

(A) In contrast to the spin-allowed transition, fluorescence has an extremely short lifespan, on the order of $10^{-8} \mathrm{~s}$.

(B) This transition (spin-forbidden transition) has lifetimes that may be several seconds or minutes long, depending on the conditions.

When describing the electrical structure of organic luminophores, a Jablonski diagram is used since spin-orbit coupling is not significant. MOF luminescence is greatly aided by the presence of the linker (discussed below). The permitted singletsinglet transition is especially important in the generation of linker excitation. In most cases, the emission comes from the lowest singlet excited state, except when nonradiative transfer to lower-lying states is seen. Because of the presence of conjugated linkers in MOF, the luminescence spectra of the material has been altered. Suh et al., (2008) found that the stacking interaction between neighbouring rings or between the MOF and the guest molecules might expand the emission spectrum, pushing it to the red compared to the emission spectrum of the 'monomeric' luminophore (s).

Intersystem crossing (ISC) luminescence is produced when a photoactivated electron decays to its lowest-lying vibrational state of the initially excited singlet, or the lowest-lying triplet, according to Kasha's rule. Franck derives the ground state using the line-like structure-Condon (FC) overlap factors with the ground state. Using the results of the spectroscopic technique in a symmetric vibrational mode makes it possible to calculate the force constant of the ground state by applying the resultant progression. This method may also determine how much distortion of the excited state occurs concerning the ground state. The HuangRhys factor, $S$, which specifies the connection between the luminous centre and the crystal lattice in solids, is responsible for determining this shift. Franck-Condon overlap factors function this value, which is the most basic definition. Smaller values of 'S' often result in the majority of the intensity being concentrated in the zero phonon line, which is a hallmark feature of lanthanoid luminescence ( $f-f$ transitions), while bigger values broaden the spectrum, pushing it farther to the red (Allendorf et al., 2009).

There are five modes for originating luminescence in MOFs depicted schematically in Fig. 1.

(a) Linkers: These are luminescent groups typically conjugated organic compounds that absorb in the UV and visible region. In this case, emission can occur directly from the linker. However, it may also involve a charge transfer with the coordinated metal ions or clusters.

(b) Metal ions that serve as a framework: Transition-metal ions with unpaired electrons have the potential to be effective 
quenchers. For example, in the presence of transitions prohibited by electric dipole selection constraints, the lanthanoid ions (Ln(III)) exhibit acute but faint luminescence. In addition, when an organic lumorophore is closed to a pore, either inside the framework or adsorbed within the pore, it may cause an antenna effect, which results in an increase in the luminescence intensity (De Lill et al., 2007). (c) Adsorbed lumophores: Metal-organicframework nanopores provide an opportunity to entrap luminescent molecules in an otherwise non-emissive
MOF.

(d) Exciplex formation: In this situation, $\pi$ $\pi$ interactions between neighbouring conjugated linkers or between a linker and a guest molecule might result in the formation of an exciting complex that is characterised by wide, featureless luminescence in most cases (McManus et al., 2007).

(e) MOF is coated with luminescent molecules: It reveals a hitherto unexplored avenue for creating multifunctional MOFs.

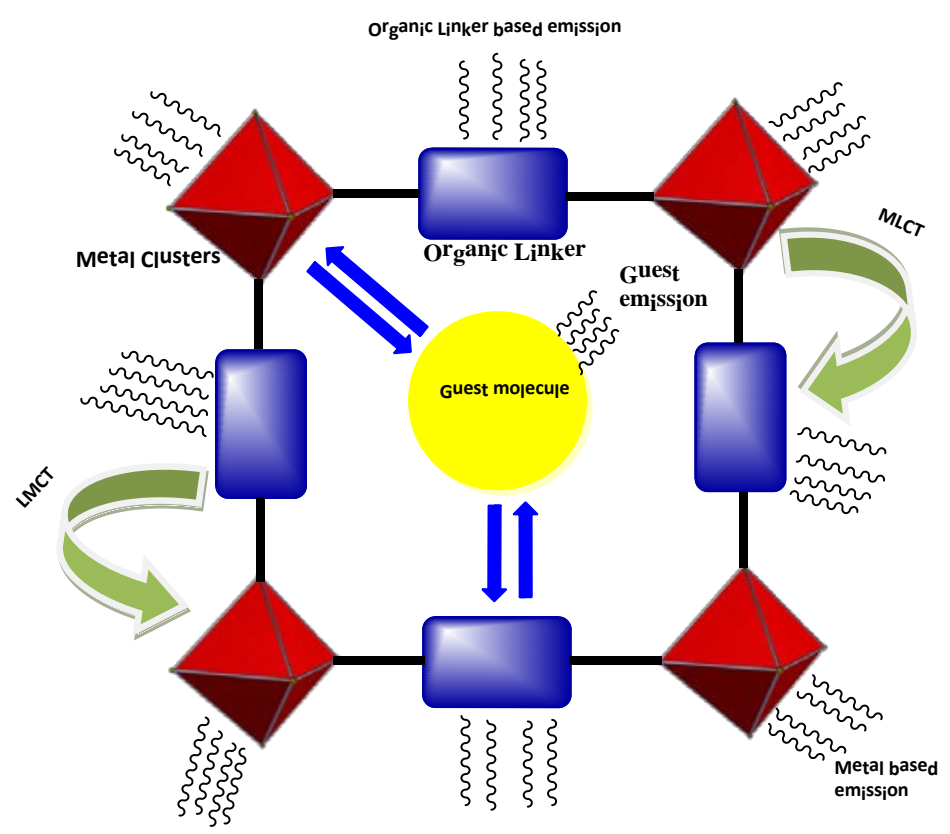

Fig. 1. In a porous MOF, a schematic illustration of the numerous emission possibilities is shown (Allendorf et al., 2009).

Organic linkers are a kind of fluorescent linker that has a $\pi$-conjugated backbone (Ravon et al., 2008) and displays negligible spin-orbit coupling. There are many different types of fluorescent linkers. As a result, the symmetry of the singlet ground and excited states plays a role in determining selection rules. Due to these considerations, the greatest emission (fluorescence) is often seen from the lowest-lying excited singlet state to the singlet ground state. Such transitions are either $\pi \rightarrow \pi^{*}$ or $n \rightarrow \pi^{*}$ in nature. It is necessary, according to Hund's rule, that a lower-lying triplet state exists, which may be accessible by non-radiative energy transfer.

On the other hand, organic species have a triplet state that is non-emissive because the spin selection criteria cannot be loosened without a significant amount of spin-orbit coupling. Despite the fact that charge transfer between the metal and the linker is involved in the process, the 
lumescence released by MOFs containing transition-metal ions is mostly localised on the linker and not on the metal. Emissions from paramagnetic transition metal complexes are not strong because the ligand-field transitions ( $d$-d) can cause a significant quenching of fluorescence generated by the organic molecule, which can occur via electron or energy transfer through the partially filled d-orbital of the transition metal complex. MOFs containing transition-metal ions without unpaired electrons, notably those containing $d^{10}$ configurations, on the other hand, may result in linker-based, highly emissive materials, as opposed to conventional MOFs (Allendorf et al., 2009).

\section{Linker-based luminescence \\ Type of linker-based luminescence}

In MOFs, there are clearly defined unique configurations of lumophores that give birth to various luminous features inside the material. MLCT (metal-to-ligand charge transfer), LMCT (ligand-to-metal charge transfer), LLCT (ligand-to-ligand charge transfer), MMCT (metal-to-metal charge transfer), ligand-centered luminescence, and metal-centred luminescence are some of the effects that have been observed. More than one competing effect might be seen (Du et al., 2008).

The spacing and arrangement of linkers in a MOF structure, the HOMO-LUMO energy gap of the organic linker(s) vs the electronic states of the metal ions, the bonding geometry, and the electronic configuration of the metal all influence the emission spectrum of the MOF structure. In the case of linker-based luminescence, a variety of transition metals have been used. $\mathrm{Zn}$ (II) and Cd(II) are two of the most frequent elements (II). However, because they have field $d$-orbitals, no $d$ - $d$ transitions are achievable with them. As a result, the emission is dependent on the electronic configuration of the metal and the orbital energy of the related metal and linker.

MOFs with identical structures but differing only in the linker may display a wide variety of emission properties, which are dependent on the linker used. The cubic IRMOF series serves as an instructive case in point (Eddaoudi et al., 2002). For example, crystals of the prototype IRMOF1, $\mathrm{Zn}_{4} \mathrm{O}(1,4 \mathrm{BDC})_{3}$, which has basic zinc acetate units connected by benzene and emits at $525 \mathrm{~nm}$ due to LMCT, have been reported to emit at this wavelength (Bordiga et al., 2004).

IRMOF-1 electronic structure has been studied in detail using ab initio methods, and it has been discovered that it is dominated by the p-orbitals of the aromatic carbon atoms, with just a little contribution from the carboxylate atoms (Civalleri et al., 2006). Furthermore, the electronic structure modelling suggested that the band gaps may be adjusted by varying the degree of conjugation in the linker. According to the research, the bandgap in IRMOF-1 is also claimed to survive when the $\mathrm{Zn}$ atom is replaced with $\mathrm{Mg}, \mathrm{Ca}, \mathrm{Be}$, or $\mathrm{Cd}$.

Interestingly, cubic MOFs having similar topologies to IRMOF-1 having linkers with a greater degree of $p$-conjugation like IRMOF-11 [ $\mathrm{Zn}_{4} \mathrm{O}(4,5,9,10$-tetra-hydropyrene 2,7-dicarboxylate) ${ }_{3}$ ], IRMOF-13 $\left[\mathrm{Zn}_{4} \mathrm{O}(2,7-\text { pyrene dicarboxylate })_{3}\right]$ and $\mathrm{Zn}_{4} \mathrm{O}(\mathrm{SDC})_{3}$ displays emission spectra similar to the linker alone. Here, the increased conjugation of these linkers is shown in Figure 2. Compared to benzene causes a decrease in the $\pi-\pi^{*}$ energy gap, and therefore the possibility for energy transfer to metal-based states becomes ineffective or is omitted entirely, localizing the emission on the linker. It is seen that the relative spatial orientations of metal units (which are mainly the same for all the 
cubic MOF) and linker s may affect this energy transfer efficiency. The zinc cluster shows a very small impact on the electronic structure of the linker. No significant interaction is noted between ligands in the structure, resulting from the similarity between the emission spectra of these MOFs and their respective linkers in solution. The exact spectral location of the emission relies on interactions between the cubic units, as these are mutually penetrated structures.

Two structures comprising 4,4'-ethyne1,2-diyldibenzoate (EDDB) and combining either dinuclear $\mathrm{Eu}(\mathrm{III})$ clusters or dinuclear $\mathrm{Zn}$ (II) clusters provide a specific illustration of the influence of the relative linker and metal energy state on emission. The former exhibits red luminescence due to energy transfer from the ligand, while the latter shows a blue-green emission that is mostly linked-based (Pham et al., 2008).
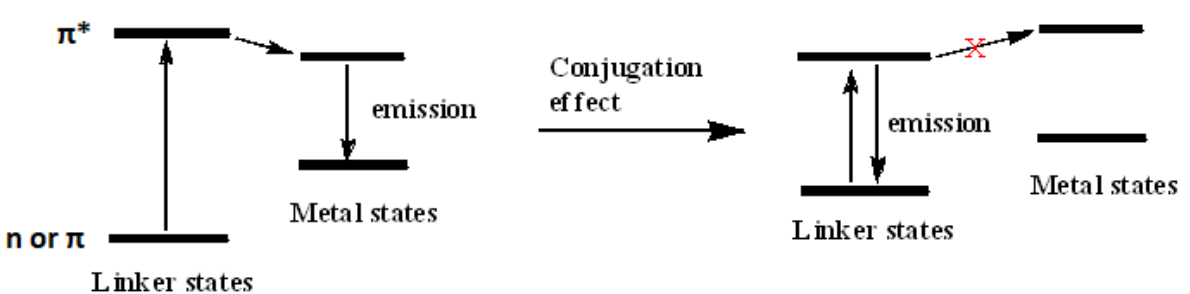

Fig. 2. Schematic representation of relative energies of the linker and metal-based states as the degree of p-conjugation increases (Allendorf et al., 2009).

\section{Ligand-to-metal charge transfer}

A variety of $\mathrm{Zn}(\mathrm{II})$ and $\mathrm{Cd}(\mathrm{II})$ MOFs, mainly those containing benzene derivatives, may show $\mathrm{LMCT}$, and these are the most often seen structures. In addition, it has been noted that they often emit a greenish-coloured emitted light. The intense $474 \mathrm{~nm}$ light following $292 \mathrm{~nm}$ excitation of a $\mathrm{Cd}$ ribbon candy-like supramolecular structure with two-fold interpenetration and 1,4-BDC linkers suggests that the structure shows two-fold interpenetration (Dai et al., 2002).

Variations in the MOFs containing BDC and $\mathrm{BTC}$ (benzene tricarboxylate) linkers indicates this. $\mathrm{Zn}_{3}(1,4-\mathrm{BDC})(1,3,5-\mathrm{BTC})_{2}$, $\left[\mathrm{NH}\left(\mathrm{CH}_{3}\right)_{2}\right]_{2}, \quad\left[\mathrm{NH}_{2}\left(\mathrm{CH}_{3}\right)_{2}\right]_{2}$ consist of a three-dimensional framework with trinuclear zinc clusters linked by BDC and BTC units, emits at $430 \mathrm{~nm}$, which is LMCT character (Ouyang et al., 2004). The energy transfer to Zn(II)-based states competes with emission from the linker, as shown by a shoulder at $370 \mathrm{~nm}$ from BTC linker emission. 1,4-BDC and 1,3,5-BTC are found in a Cd MOF. Due to LMCT, there are two emission peaks on the spectrum (Allendorf et al., 2009). For metal valence states, it has been shown that when the number of carboxylate substituents grows in BTC rather than BDC, LUMO energy drops, and HOMO energy rises. The linker modifications may see the structure's effect on the transition between LMCT and linker-based emission. For example, replacing the linker from 1,3,5-BTC to 1,2,4-BTC yields a 3-D pillared MOF, $\mathrm{Cd}_{3}(1,2,4-\mathrm{BTC})_{2}\left(\mathrm{H}_{2} \mathrm{O}\right)_{6} \cdot 3 \mathrm{H}_{2} \mathrm{O}$ with strong blue luminescence at $\lambda_{\max }=436 \mathrm{~nm}$ upon $328 \mathrm{~nm}$ excitation, that is due to LMCT (Fan et al., 2003) instead of linker based emission. Other benzene-based carboxylate linkers containg MOFs including a $\mathrm{Cd}$ framework containing 1,4-BDC, 1,3,5-BTC, and 4,4'-bipyridine (4,4'-bipy) with emission peaks at 416, 515,360 and 481 $\mathrm{nm}\left(\lambda_{\mathrm{ex}}=311 \mathrm{~nm}\right)$ exhibit LMCT (Dai et al., 2003). A lead complex consisting of octanuclear $\mathrm{Pb}(\mathrm{II})$ centres with emission at $424 \mathrm{~nm}$ also shows LMCT (Yang et al., 103 2008). 
Int. J. Exp. Res. Rev., Vol. 26: 99-113 (2021)

The luminescence of MOFs with heteroatom-substituted linkers has been described. These metal-organic frameworks, which comprise a linker of 4,5-bis(4-pyridyl)-1,2,4 triazole (BPT), and one of the three BDC isomers, display both linker-centred luminescence and LMCT (Wang et al., 2007). Imidazole 4,5dicarboxylate and 4,4'-bipy MOFs exhibit LMCT-like emission at 437, 441, and 455, respectively (Lu et al., 2006). Cd(II) and $\mathrm{Zn}$ (II) MOF consist of imidazole-4,5dicarboxylate and 4,4'-bipy building blocks emitted at $555 \mathrm{~nm}$ upon excitation at $\lambda_{\text {ex }}=$ $467 \mathrm{~nm}$ ) and $564 \mathrm{~nm}$ upon excitation at $\lambda_{\mathrm{ex}}$ $=470 \mathrm{~nm}$ ), respectively (Allendorf et al., 2009).

MOF luminescence can be tuned which is provided by Huang et al., who demonstrated that emission can be toggled between linker-based and LMCT processes in the hydrated versus dehydrated crystals of $\left[\mathrm{Cd}_{3}\right.$ (2,6-di-(4triazolyl)pyridine $\left.)_{6}\right]\left(\mathrm{BF}_{4}\right)_{2}\left(\mathrm{SiF}_{6}\right)(\mathrm{OH})_{2} \cdot 13.5 \mathrm{H}$ ${ }_{2} \mathrm{O}$ (Huang et al., 2006). Due to linkerbased luminescence in the UV, water in the lattice limits efficient energy transmission from the linker to metal centres (382 nm). On the other hand, dehydration leads in the formation of LMCT, which emits light at $438 \mathrm{~nm}$. Based on the ion radius and coordination geometry, the LMCT or linkerbased luminescence of $\mathrm{Cd}, \mathrm{Zn}$, and $\mathrm{Hg}$ containing MOFs is determined by the linker 5-(2-pyridyl)-1,3,4-oxadiazol-2-thione (Wang et al., 2007).

\section{Synthesis of MOFs which exhibit LMCT}

Synthesis of ribbon-candy-like supramolecular structure of $\mathrm{Cd}$ (II) (1)

It is synthesized by the hydrothermal reaction of $\mathrm{H}_{2} \mathrm{tp}$ ( $\mathrm{tp}=$ terephthalate), $\left[\mathrm{Ph}_{3} \mathrm{PCH}_{2} \mathrm{Ph}\right] \mathrm{Cl}$ and water with $\mathrm{Cd}\left(\mathrm{CH}_{3} \mathrm{CO}_{2}\right)_{2} \cdot 2 \mathrm{H}_{2} \mathrm{O}$ with the two-fold interpenetration of an unprecedented 3D
$8^{2} 10$-a net formed by polymer $\left\{\left[\mathrm{Ph}_{3} \mathrm{PCH}_{2} \mathrm{Ph}\right][\mathrm{Cd}(\mathrm{tp}) \cdot \mathrm{Cl}] \cdot 2 \mathrm{H}_{2} \mathrm{O}\right\}$ n containing giant rhombic channels, which displays strong fluorescent emission in the solidstate ( Dai et al., 2002).

Synthesis of the MOF
$\left[\mathrm{Cd}_{3}(\mathrm{BTC})_{2}\left(\mathrm{H}_{2} \mathrm{O}\right)_{6}\right] \cdot 3 \mathrm{H}_{2} \mathrm{O}(2)$
Using the piperidinium salt of tri-mellitic acid $\left(\mathrm{BTC}^{3-}\right)$ and cadmium(II) acetate dihydrate, an unprecedented 3D pillared MOF was created. The 'floors' of the BTC3benzene rings are directly related to the pillars of the $4.8^{2}$ topological channels (Fan et al., 2003).

\section{Synthesis of $\left\{\mathrm{Pb}_{4}(\mathrm{Bdc})_{3}\left(\mu_{4}-\mathrm{O}\right)\left(\mathrm{H}_{2} \mathrm{O}\right)\right\}_{\mathrm{n}}$ (3)}

Hydrothermal circumstances result in the self-assembly of $\mathrm{Pb}\left(\mathrm{NO}_{3}\right)_{2}$, isophthalic acid, and 1,2,4-triazole to form this 3D framework of lead(II) octanuclear cores, which may be characterised as secondary building blocks (Yang et al., 2008).

\section{Synthesis of $\left[\mathrm{Zn}_{3}(\mathrm{IDC})_{2}(\mathrm{bpy})\left(\mathrm{H}_{2} \mathrm{O}\right)_{2}\right]_{n}(4)$}

It is synthesized by a mixture of $\mathrm{ZnSO}_{4}, 7 \mathrm{H}_{2} \mathrm{O}(0.144 \mathrm{~g}, 0.50 \mathrm{mmol})$, $\mathrm{H}_{3} \mathrm{IDC}(0.078 \mathrm{~g}, 0.50 \mathrm{mmol})$, bpy $(0.078$ g, $0.50 \mathrm{mmol})$, py $(0.50 \mathrm{~mL})$, and water $(10 \mathrm{~mL})$ was sealed in a $25 \mathrm{~mL}$ stainless steel vessel (Teflon lined) and heated at $180^{\circ} \mathrm{C}$ for 3 day. After that it is cooled to $100^{\circ} \mathrm{C}$ at a rate of $10^{\circ} \mathrm{C} / \mathrm{h}$ and remains at this temperature for $10 \mathrm{~h}$ and then cooled to room temperature. Then colourless prism-shaped crystals were collected, washed with distilled water, and dried in air. This compound could also be obtained in by the hydrothermal reactions of $\mathrm{Zn}$ salts, $\mathrm{H}_{3}$ IDC, and bpy with the following different molar ratios in $10 \mathrm{~mL}$ of water and $0.5 \mathrm{~mL}$ of py (or adjust $\mathrm{pH}$ value to 8 with $\mathrm{NaOH}$ ) at $180^{\circ} \mathrm{C}$ for 3 days (Lu et al., 2006). 


\section{Metal-to-ligand charge transfer}

Metal-to-linker charge transfer is commonly observed in $d^{10} \mathrm{Cu}(\mathrm{I})$ and $\mathrm{Ag}(\mathrm{I})$ based MOFs. In these metals, the $d$ electrons are usually present in the valance orbital, which enables the MLCT, and in $\mathrm{Cd}(\mathrm{II})$ and $\mathrm{Zn}$ (II) are core-like orbitals. Paramagnetic $d^{9} \mathrm{Cu}(\mathrm{II})$ containing MOFs can quench ligand-centred luminescence as observed in comparisons between many $\mathrm{Zn}$ (II) and/ or Cd(II) MOFs (Frisch et al., 2005; Gunning et al., 2005; Wang et al., 2007). Metal-based emission is also quenched by $\mathrm{Cu}(\mathrm{II})$. As an example, the uranyl complex $\mathrm{UO}_{2}\left(\mathrm{C}_{5} \mathrm{H}_{2} \mathrm{~N}_{2} \mathrm{O}_{4}\right) \cdot \mathrm{H}_{2} \mathrm{O}$ exhibits characteristic $\mathrm{UO}_{2}{ }^{2+}$ emission spectra, whereas it's $\mathrm{Cu}(\mathrm{II})$-doped analogue $\mathrm{UO}_{2}$ (3,5-pyrazole dicarboxylate) $\left(\mathrm{H}_{2} \mathrm{O}\right)$ results in no emission, regardless of excitation wavelength (Frisch et al., 2005).

Similarly, the heterometallic MOFs $\mathrm{Cu}_{3}$ (trans-3-(3-pyridyl)acrylate) ${ }_{6} \mathrm{Nd}_{2}\left(\mathrm{NO}_{3}\right)_{6}$ and the homometallic $\mathrm{Nd}\left(\mathrm{C}_{8} \mathrm{H}_{6} \mathrm{NO}_{2}\right)_{3} \cdot \mathrm{H}_{2} \mathrm{O}$ have similar absorption spectra though the presence of $\mathrm{Cu}(\mathrm{II})$ in the first MOF quenches the luminescence(Gunning et al., 2005). A wide varity of MOF can be formed with copper coordination compounds as $\mathrm{Cu}$ can adopt three-, four-, five or sixcoordinate geometries. As an example, $\mathrm{Cu}$ (2,9-dimethyl1,10-phenanthroline) ${ }_{2}$ (1,4BDC $)_{1 / 2}\left(1,4-\mathrm{H}_{2} \mathrm{BDC}\right)_{1 / 2 .} 2 \mathrm{H}_{2} \mathrm{O}$ emits at 626 $\mathrm{nm}$ with excitation at $375 \mathrm{~nm}$ (Allendorf et al., 2009).

Metal-to-ligand charge transfer is also observed in cyano-bridged copper(II)copper(I) mixed-valence polymers [Cu(1,2propane diamine $\left.)_{2}\right]\left[\mathrm{Cu}_{2}(\mathrm{CN})_{4}\right]$ and $\left[\mathrm{NEt}_{4}\right]\left[\mathrm{Cu}_{2}(\mathrm{CN})_{3}\right]$ due to copper-to-cyanide transfer, which is more effective for the latter species (Colacio et al., 2002). The complex $\mathrm{Cu}(1,2,4-\mathrm{BTC})\left(2,2^{\prime}\right.$-bipy) display intense blue emission. These mixedvalence complexes also exhibit intervalence charge transfer (IVCT). A few examples of silver MOFs have been reported which exhibits MLCT. The 2-D layered structure $\quad \mathrm{Ag}[4-$ (2pyrimidylthiomethyl) benzoate] upon excitation at $\lambda=370 \mathrm{~nm}$ produces a strong green coloured emission with a peak highest at $530 \mathrm{~nm}$, due to LMCT and MLCT (Yin et al., 2009). The complex $\left[\operatorname{Ag}\left(4,4^{\prime}-\right.\right.$ bipy $)]_{n}[\operatorname{Ag}(1,2,4-H B T C)]_{n}$ exhibits an intense fluorescent emission upon excitation at $410 \mathrm{~nm}$ including a maximum at 502nm due to MLCT (Zhou et al., 2008).

\section{Synthesis of some MOFs which exhibit MLCT}

Synthesis of $\left[\mathrm{UO}_{2}\left(\mathrm{C}_{5} \mathrm{H}_{2} \mathrm{~N}_{2} \mathrm{O}_{4}\right)\left(\mathrm{H}_{2} \mathrm{O}\right)\right]$ (5)

For the synthesis of this compound, the mixture of $\mathrm{UO}_{2}\left(\mathrm{NO}_{3}\right)_{2} \cdot 6 \mathrm{H}_{2} \mathrm{O} \quad(503 \mathrm{mg}$, $1.0 \mathrm{mmol}), \mathrm{H}_{3} \mathrm{pdc}(86 \mathrm{mg}, 0.5 \mathrm{mmol})$ and $\mathrm{H}_{2} \mathrm{O}(1.39 \mathrm{~mL}, 77.2 \mathrm{mmol})$ in the molar ratio of $2: 1: 154$ was taken in a $23 \mathrm{~mL}$ Teflon-lined stainless steel Parr $^{R}$ bomb (initial $\mathrm{pH}=1.45$ ) and heated to $180^{\circ} \mathrm{C}$ for 3 days. Then the Parr bomb was kept cooling down to room temperature. The yellow coloured mother liquor having final $\mathrm{pH}=$ 1.31, was extracted. The remaining yellow crystals were washed with distilled water and ethanol and then dried in the oven at $50^{\circ} \mathrm{C}$ ( $156 \mathrm{mg}, 29.4 \%$ yield based on $\mathrm{H}_{3} \mathrm{pdc}$ ) (Frisch et al., 2005).

\section{Synthesis of $\left[\left(\mathrm{UO}_{2}\right) \mathrm{Cu}\left(\mathrm{C}_{5} \mathrm{H}_{2} \mathrm{~N}_{2} \mathrm{O}_{4}\right)_{2}\left(\mathrm{H}_{2} \mathrm{O}\right)_{2}\right]$} (6)

This compound was obtained by mixing $\mathrm{UO}_{2}\left(\mathrm{NO}_{3}\right)_{2} \cdot 6 \mathrm{H}_{2} \mathrm{O} \quad(251 \mathrm{mg}, 0.5 \mathrm{mmol})$, $\mathrm{Cu}\left(\mathrm{NO}_{3}\right)_{2} \cdot 2.5 \mathrm{H}_{2} \mathrm{O}$ (116mg, $\left.0.5 \mathrm{mmol}\right), \mathrm{H}_{3} \mathrm{pdc}$ (88mg, $0.5 \mathrm{mmol})$ and $\mathrm{H}_{2} \mathrm{O}(1.35 \mathrm{~mL}$, $75 \mathrm{mmol}$ ) in the molar ratio of 1:1:1:150 in a $23 \mathrm{~mL}$ Teflon-lined stainlesssteel Parr $^{R}$ bomb (starting $\mathrm{pH}=1.27$ ) and heated to $120^{\circ} \mathrm{C}$ for 1 day. Then the Parr bomb was allowed to cool to room temperature. The green mother liquor (final $\mathrm{pH}=1.00$ ) was then extracted, and the remaining clusters of green crystals were washed with both distilled water and ethanol and then allowed to dry in a $50^{\circ} \mathrm{C}$ oven in the air (Frisch et al., 2005). 


\section{Synthesis of heterometallic $\left[\mathrm{Cu}_{3}\left(\mathrm{C}_{8} \mathrm{H}_{6} \mathrm{NO}_{2}\right)_{6} \mathrm{Nd}_{2}\left(\mathrm{NO}_{3}\right)_{6}\right](7)$}

For the synthesis of this compound a mixture of $\mathrm{Nd}\left(\mathrm{NO}_{3}\right)_{3} \cdot 6 \mathrm{H}_{2} \mathrm{O}$, $\mathrm{Cu}\left(\mathrm{NO}_{3}\right)_{2} \cdot 5 \mathrm{H}_{2} \mathrm{O}, \quad \mathrm{C}_{8} \mathrm{H}_{7} \mathrm{NO}_{2}$ (3-HPY), $\mathrm{NH}_{4} \mathrm{OH}(\mathrm{aq})$ and $\mathrm{H}_{2} \mathrm{O}$ in the ratio $1: 1: 1: 2$ : 151 was placed in a Teflon-lined autoclave $\left(\mathrm{Parr}^{\mathrm{R}}\right.$ bomb) $(\mathrm{pH}=3.00)$ and heated statically at $120^{\circ} \mathrm{C}$ for 72 hours under autogenous pressure. Then it was cooled to room temperature. Then aqueous supernatant $(\mathrm{pH}=2.67)$ was blend. Then the products were repeatedly washed with ethyl alcohol and water. It was then dried at room temperature. Violet coloured hexagonal anti-prismatic crystals of $\left[\mathrm{Cu}_{3}\left(\mathrm{C}_{8} \mathrm{H}_{6} \mathrm{NO}_{2}\right)_{6} \mathrm{Nd}_{2}\left(\mathrm{NO}_{3}\right)_{6}\right]$ were isolated for single-crystal analysis (Gunning et al., 2005).

\section{Synthesis of homometallic $\left[\mathrm{Nd}\left(\mathrm{C}_{8} \mathrm{H}_{6} \mathrm{NO}_{2}\right)_{3} \mathrm{H}_{2} \mathrm{O}\right](8)$}

This compound is synthesized by mixing $\mathrm{Nd}\left(\mathrm{NO}_{3}\right)_{3} \cdot 6 \mathrm{H}_{2} \mathrm{O}, \mathrm{C}_{8} \mathrm{H}_{7} \mathrm{NO}_{2}, \mathrm{NH}_{4} \mathrm{OH}$ and $\mathrm{H}_{2} \mathrm{O}$ in the ratio $1: 1: 2: 151(\mathrm{pH}=5.20)$ and treated in a fashion similar to that described for the previous compound. Pink, rod-like crystals of the compound from a solution $(\mathrm{pH}=5.30)$ were isolated for single-crystal analysis (Gunning et al., 2005).

\section{Luminescense from linkers}

As we have already discussed, if we increase the conjugation of the linker beyond benzene for cubic $\mathrm{Zn}_{4} \mathrm{O}$-based MOFs, we can see emissions from linkers. The Increased linker rigidity, which is the result of metal coordination often lowers the non-radiative decay rate, contrastingly it increases the intensity of fluorescence of the linker, permitting the vibrational finestructure to be observed an increase in the fluorescence lifetime and quantum yields by reducing the efficiency of non-radiative pathways (Allendorf et al., 2009). Although cases of decreased intensity are reported, an enhancement in emission intensity is usually observed. As an example, a mixedmetal complex consisting of $\mathrm{Zn}(\mathrm{II})$ and $\mathrm{Cu}(\mathrm{I})$ $\left.\left[\mathrm{Zn}_{3}(\mathrm{Cu})_{2} \text { (isonicotinate) }\right)_{8}\right]$ emits strong blue luminescence from a linker which is weakly fluorescent in solution (Feng et al., 2007).

The emission characteristics of the material (intra-linker or inter-linker-based) are determined by the degree of isolation between the linkers in the structure (intralinker or inter-linker-based), which is affected by the metal's size, the SBU structure, and the linkers' orientation. Same linker incorporated in two different MOF geometries results in different emission colours associated directly with the degree of $\pi$-overlap of the organic linkers. Both the structures, a 2-D net $\left(\mathrm{Zn}_{3}(\mathrm{SDC})_{3}(\mathrm{DMF})_{2}\right)$ and a cubic 3-D framework $\left(\mathrm{Zn}_{4} \mathrm{O}(\mathrm{SDC})_{3}\right)$ (formed via alterations to the synthetic method) show distinctive linker-centered emission in the solid-state. The optical properties of the MOFs can be directly related to the linker environment, which their crystal structure can obtain. The low-density 3-D crystals, having minimal short-range co facial distances between the stilbene, resulting from minimal inter-luminophore interactions. It is observed that a bright purple-blue emission occurs with increased lifetime with mono-exponential fluorescence decay, compared to the linker in the solution. On the other hand, the 2-D structure, having shorter co facial distances between the stilbene linkers, resulted in a red-shifted emission with a bi-exponential decay with two characteristic lifetimes, indicating contributions of both monomeric and interacting stilbenes to the emission (Bauer et al., 2007).

The metal centres in the 2-D structure 
can be altered to identify the affect of the metal ion on the luminescence properties. For example, $\mathrm{Cd}$ (II) and $\mathrm{Mn}$ (II) compounds were prepared with the same structure as the 2-D Zn MOF. The $\mathrm{Cd}(\mathrm{II})$ ion having $\mathrm{d}^{10}$ configuration yielded a bright crystalline compound. On the other hand the structure containing high-spin $\mathrm{d}^{5} \mathrm{Mn}$ (II) displays significantly quenched emission (Allendorf et al., 2009). All emission spectra are nearly similar in shape and position, indicating that the emission properties are dominated by throughspace overlap of the linkers, and the coordination to metals of deferent Lewis acidities do not play a major role. Ability of MOFs to 'isolate' linkers in space produces 'solution-like' emission from the linker. The interactions in lumophores in open, lowdensity structures is minimized, which removes the broadening and red-shifts typically observed for solid samples of the ligands themselves.

Except $\mathrm{Cd}(\mathrm{II})$ and $\mathrm{Zn}$ (II) MOFs, which are the most commonly reported luminescent MOFs, there are a few reports based on $\mathrm{Ag}(\mathrm{I})$. The structure of $[\mathrm{Ag}(\mathrm{H}-$ TPT) $\left.\mathrm{NO}_{3}\right] \mathrm{NO}_{3} \cdot 4 \mathrm{H}_{2} \mathrm{O}$ (where TPT $=2,4,6$ tris(4-pyridyl)-1,3,5-triazine), in which $\mathrm{Ag}(\mathrm{I})$ is trigonally coordinated by two pyridyl $\mathrm{N}$ and one nitrato ' $O$ ' to form a 1-dimensional zigzag chain, displays linker-based luminescence(Li et al., 2008) at nearly the same wavelength as for the free ligand $\left(\lambda_{\max }=430 \mathrm{~nm}\right.$ vs. $\left.\lambda_{\max }=469 \mathrm{~nm}\right)$. The 1-D chain structure $\left[\mathrm{Ag}_{2}(\mathrm{~L})\left(\mathrm{L}^{\prime}\right)\right] \quad\left(\mathrm{ClO}_{4}\right)_{2}$, containing both a macro cyclic bis(biphenylene-diethylenetriamine) linker (L) and linear linker ( $L^{\prime}=1,6$-bis(4-imidazol10-ylmethylphenyl) 2,5-diazahexane), exhibits linker-centered luminescence at $413 \mathrm{~nm}$ upon excitation at $350 \mathrm{~nm}$, which is dominated by the free macro cyclic ligand $L\left(\lambda_{\max }=417 \mathrm{~nm}\right.$ ) (Allendorf et al., 2009). Five structures based on the same linker, 2,3-bis(triazol-1ylmethyl) quino- xaline (BTMQ), emitted similar luminescence (Du et al., 2008). These compounds having empirical formula: $\mathrm{Zn}(\mathrm{BTMQ}) \mathrm{Cl}_{2}, \quad \mathrm{Zn}(\mathrm{BTMQ})_{2} \quad\left(\mathrm{NO}_{3}\right)_{2}$,

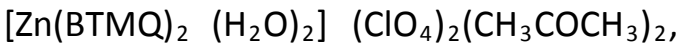
$\left[\begin{array}{llll}\mathrm{Cd}(\mathrm{BTMQ})_{2} & \left(\mathrm{H}_{2} \mathrm{O}\right)_{2}\end{array}\right]\left(\mathrm{ClO}_{4}\right)_{2}\left(\mathrm{H}_{2} \mathrm{O}\right)_{6}$ and $[\mathrm{Ag}(\mathrm{BTMQ})]\left(\mathrm{ClO}_{4}\right)\left(\mathrm{H}_{2} \mathrm{O}\right)_{1.5}$. Although the structures are not same, the common factor is a $\mathrm{d}^{10}$ metal and an emissive linker. Analogous structures with $\mathrm{Mn}$ (II) metal centers which exhibit no emission, probably due to quenching effects, as discussed earlier. Usually most of the complexes were excited at ca. $287 \mathrm{~nm}$ and had main emission bands at ca. $394 \mathrm{~nm}$. These emissions can be conceived as intralinker $\left(n-\pi^{*}\right.$ or $\left.\pi-\pi^{*}\right)$ emissions upon excitation at $290 \mathrm{~nm}$ similar emissions are observed at $396 \mathrm{~nm}$ for the free BTMQ ligand.

\section{Synthesis of MOFs which exhibit} luminescence from the linkers

Synthesis of $\mathrm{Zn}(\mathrm{H}-\mathrm{Norf})_{2},\left(\mathrm{NO}_{3}\right)_{2}, \mathbf{2 H}_{2} \mathrm{O}$ (9)

This compound is synthesized by mixing $\mathrm{Zn}\left(\mathrm{NO}_{3}\right)_{2}, 6 \mathrm{H}_{2} \mathrm{O}$ and $\mathrm{H}$-Norf $(2 \mathrm{mmol})$ in a mortar with a pestle and placed in a thickwalled Pyrex tube (ca. $20 \mathrm{~cm}$ long). Then $1.5 \mathrm{~mL}$ of $\mathrm{H}_{2} \mathrm{O}$ and $0.5 \mathrm{~mL}$ of EtOH were added. After that the tube was cooled with liquid $\mathrm{N}_{2}$, evacuated under vacuum. After that, it was finally flame-sealed. The tube was heated at $110^{\circ} \mathrm{C}$ for 1 day. The colourless block crystals (one phase) were harvested (Chen et al., 2001).

Synthesis of $\left\{\left[\mathrm{Ag}(\mathrm{Htpt})\left(\mathrm{NO}_{3}\right)\right] \mathrm{NO}_{3} \cdot 4 \mathrm{H}_{2} \mathrm{O}\right\}_{\mathrm{n}}$ (10)

For the synthesis of this compound a mixture of tpt $(0.10 \mathrm{mmol}), \mathrm{AgNO}_{3}(0.30$ mmol), and 2 drops concentrated $\mathrm{HNO}_{3}$ in $8 \mathrm{~mL}$ water was sealed in a $15 \mathrm{~mL}$ Teflonlined stainless steel reactor. The reactor was held at $180^{\circ} \mathrm{C}$. After $48 \mathrm{~h}$ colorless needle crystals were obtained. The crude product was washed with water to give compound ( $\mathrm{Li}$ et al., 2008). 
Synthesis of $\left\{\left[\mathrm{Cu}_{2}(\mathrm{tpt})_{2}\left(\mathrm{SO}_{4}\right)_{2}\left(\mathrm{H}_{2} \mathrm{O}\right)_{2}\right] \cdot 4 \mathrm{H}\right.$ $\left.{ }_{2} \mathrm{O}\right\}_{\mathrm{n}}(11)$

For the synthesis of this compound, a mixture of $\mathrm{CuSO}_{4} \cdot 5 \mathrm{H}_{2} \mathrm{O}(0.20 \mathrm{mmol})$, tpt $(0.20 \mathrm{mmol})$, and water $(10 \mathrm{~mL})$ was sealed in a $15 \mathrm{~mL}$ Teflon-lined stainless steel reactor. The reactor was held at $140^{\circ} \mathrm{C}$. After $72 \mathrm{~h}$, dark-green block crystals were obtained (Li et al., 2008).

\section{Luminescent metal-organic-frameworks as sensors}

According to many recent studies, Luminescent MOFs can be employed as chemical sensors (Doty et al., 2009; Orellana, 2006; Pickup et al., 2005; Pal et al., 2021; Wolfbeis, 2005). The wide range of MOFs and the materials' synthetic adaptability make them excellent for molecular identification. A useful MOF sensor should have the following characteristics: I it must change its response whenever it interacts with an analyte; (ii) the change must be specific to that analyte; (iii) the response should be reversible (this is desirable but not required in all cases); and (iv) the change must be detectable. The fact that luminescence can be detected makes it more exciting than light absorption, which is more sensitive. Photon counting algorithms may detect even tiny amounts of photons, especially in the absence of a significant background signal. As a result, molecular detection through luminescence has advanced to a high level of excellence (Allendorf et al., 2009; Zhao et al., 2004). In luminous MOFs, a variety of mechanisms are possible. The following processes are involved: (a) solvochromatic shifts; (b) electronic structure modification due to coordination sphere alternations; (c) fluorescence quenching by adsorbed species; and (d) exciplex generation.

\section{The solvatochromatic effect}

It is generally described as a shifting of wavelength in an absorption band observed when the solvent polarity is changed, which can also be found in fluorescence emission spectra (Allendorf et al., 2009). For the MOFs (which do not dissolve) the effect is the result of changes in the polarity of adsorbed guest molecules. Lee et al. observed this in a permeable MOF $\mathrm{Zn}_{4} \mathrm{O}(\mathrm{NTB})_{2}$.3DEF.EtOH, in which the presence or absence of $\pi-\pi$ interactions (desolvated versus solvated form, respectively) between inter penetrated nets results in a red-shift in the luminescence maximum (Lee et al., 2005). The magnitude of the shift depends on the structure of the guest molecule, with $\lambda_{\max }$ (pyridine) $<\lambda_{\max }($ methanol $)<\lambda_{\max }$ (benzene).

\section{Changes in the coordination sphere}

It can produce more substantial changes in the luminescence spectrum than simple uptake of guest molecules. Due to their large coordination sphere, Lanthanoidcontaining MOFs are effective for sensor applications. The coordination geometry of $\mathrm{Ln}(\mathrm{III})$ is not rigid so it can coordinate guest molecules even if the lanthanoid is part of the framework. Yaghi and coworkers (Yaghi et al., 1999) have synthesized the terbium MOF $\quad \mathrm{Tb}_{2}(1,4-\mathrm{BDC})_{3} . \quad\left(\mathrm{H}_{2} \mathrm{O}\right)_{4} \quad$ (MOF-76) proposed that such MOFs could be used in chemical sensing because the water molecules in this MOF are exchangeable and exposure to $\mathrm{NH}_{3}$ results in complete replacement of the four coordinated drinks of water and decreases the luminescence decay constant. So from the above discussion, it can be said that lanthanoid can either increase or decrease the luminescence intensity. Chen and coworkers (Chen et al., 2007) used the 
euanalogue of MOF-76. In this case, the luminescence decreases when exposed to acetone, but increases when exposed to DMF, which dictates that modulations in the MOF luminescence can also be used as a detection method (Rao et al., 2012).

\section{Luminescence quenching by adsorbed species}

Adsorbed guests molecule can modulate the luminescence intensity through indirect interactions with the metal ions in a framework. In the case of anions the size, hydrogen-bonding ability, and the structure of the MOF itself contribute to the observed effects. There are four examples the $1^{\text {st }}$ one is MOF-76b (B. Chen et al., 2008), in which guest $\mathrm{MeOH}$ occupy the exchangeable sites on the $\mathrm{Tb}(\mathrm{III})$ that exhibits increased luminescence upon exposure to solutions of a range of anions. On the other hand halide ions, in particular $\mathrm{F}$-, increase the luminescence intensity by as much as a factor of four over the MOF in the absence of anion. The $\mathrm{H}$-bonding interactions between the $F^{-}$and axially coordinated methanol are thought to affect the $\mathrm{O}-\mathrm{H}$ stretching frequency of the methanol, reducing its ability to quench the fluorescence. In the second example, $\mathrm{Tb}$ (mucicate) ${ }_{1.5}\left(\mathrm{H}_{2} \mathrm{O}\right)_{2} .5 \mathrm{H}_{2} \mathrm{O}$, reported by Wong et al., (2006) responds to halides as well, but $\mathrm{CO}_{3}{ }^{2-}$ and $\mathrm{CN}^{-}$produce even greater luminosity enhancements.

Interestingly very little enhancement produced by $\mathrm{NO}_{3}{ }^{-}$, suggesting that hydrogen bonding is not the primary factor in this case (the pKa of $\mathrm{CO}_{3}{ }^{2-}$ and $\mathrm{NO}_{3}{ }^{-}$ obviously being quite deferent), even though the musical linker has four $-\mathrm{OH}$ groups. In a third example, Pham et al. proposed synthesising a 3-D Eu(III) framework linked with EDDB(Pham et al., 2008). Luminescence studies dictate the characteristic lines of Eu corresponding to the ${ }^{5} \mathrm{D}_{0}$ to ${ }^{7} \mathrm{~F}_{\mathrm{J}}$ transitions. ON the other hand
Introduction of a neutral guest, in this case, iodine induces luminescence quenching. This is due to forming a charge-transfer complex between the conjugated linker and the iodine guest. Removal of the iodine showed results in recovery of framework luminescence. Finally, Bai et al. showed that aromatic molecules in water could be identified by their quenching of the luminescence from a two-dimensional porous MOF containing $\mathrm{Cu}(\mathrm{I})$ ions (Bai et al., 2006). This MOF consists of a Cu6L6 cluster ( $\mathrm{L}=$ 5,6-diphenyl-1,2,4triazine-3thiolate), in which the $\mathrm{Cu}(\mathrm{I})$ ions are coordinated by two thiolate sulfur atoms one triazine nitrogen. Various methylbenzene, Toluene, nitrobenzene, and aniline quench the fluorescence to some degree. The magnitude of the quenching is not strongly altered by the electron-donating or electron-withdrawing groups on the aromatic ring. Bacterial Spore can be Detected by $\left[\mathrm{Tb}^{3+}\right.$ (macrocycle) (dipicolinate)] Luminescence (Rieter et al., 2007; Rosen et al., 1997).

\section{Conclusion}

The creation of luminescent MOFs is still in its early stages. As seen by the several examples given above, these materials provide a wide range of study possibilities. The mix of organic and inorganic components, synthetic adaptability, and nanoporosity opens up a world of possibilities not found in other materials classes. To create luminescence, both the metal and the linker may be needed. Chemical sensing, as a consequence, is a potential application.

In addition, given the large surface areas accessible in a few MOFs, hybrid materials that act as both a detection medium and a pre-concentrator may be developed. Finally, MOF structures' structured character implies that they might be used 
as a platform for studying energy transfer and other photophysical effects. As a result, these materials are anticipated to be the source of numerous technical and scientific breakthroughs in this rapidly evolving field.

\section{Acknowledgements}

This study was made possible by supporting WBDST grants, Sanction No. 203 (Sanc.)/ST/P/S\&T/15G32/2017.

\section{References}

Allendorf, M. D., Bauer, C. A., Bhakta, R. K. and Houk, R. J. T. (2009). Luminescent metal-organic frameworks. Chemical Society Reviews. 38(5): 1330-1352.

Bai, Y., He, G., Zhao, Y., Duan, C., Dang, D. and Meng, Q. (2006). Porous material for Absorption and Luminescent Detection of Aromatic Molecules in Water. 1(14): 1530-1532.

Bauer, C. A., Timofeeva, T. V, Settersten, T. B., Patterson, B. D., Liu, V. H., Simmons, B. A. and Allendorf, M. D. (2007). Influence of connectivity and porosity on ligand-based luminescence in zinc metal-organic frameworks. Journal of the American Chemical Society. 129(22): 71367144.

Cahill, C. L., De Lill, D. T. and Frisch, M. (2007). Homo- and heterometallic coordination polymers from the $f$ elements. Cryst. Eng. Comm. 9(1): 1526.

Chen, B., Wang, L., Zapata, F., Qian, G. and Lobkovsky, E. B. (2008). A Luminescent Microporous Metal Organic Framework for the Recognition. J. Am. Chem. Soc. 130: 6718-6719.

Chen, B., Yang, Y., Zapata, F., Lin, G., Qian, G. and Lobkovsky, E. B. (2007). Luminescent open metal sites within a metal-organic framework for sensing small molecules. Advanced
Materials. 19(13): 1693-1696.

Chen, Z. F., Xiong, R. G., Zhang, J., Chen, X. T., Xue, Z. L. and You, X. Z. (2001). 2D molecular square grid with strong blue fluorescent emission: A complex of norfloxacin with zinc(II). Inorganic Chemistry. 40(16): 4075-4077.

Colacio, E., Kivekăs, R., Lloret, F., Sunberg, M., Suarez-Varela, J., Bardají, M. and Laguna, A. (2002). Architecture dependence on the steric constrains of the ligand in cyano-bridged copper(I) and copper(II)-copper(I) mixed-valence polymer compounds containing diamines: Crystal structures and spectroscopic and magnetic properties. Inorganic Chemistry. 41(20): 5141-5149.

Dai, J.-C., Hu, S.-M., Wu, X.-T., Fu, Z.-Y., Du, W.-X., Zhang, H.-H. and Sun, R.-Q. (2003). A novel 2D bilayer architecture generated via $\pi-\pi$ interactions and host-guest molecular recognition: assembly and structure of $\{[\mathrm{Cd}(\mathrm{Htma})$ (bpy) $\left.\left.\left(\mathrm{H}_{2} \mathrm{O}\right)\right] \cdot\left(\mathrm{H}_{2} \mathrm{tp}\right) 0.5 \cdot 2 \mathrm{H}_{2} \mathrm{O}\right\} \quad \mathrm{n}$ polymer $\left(\mathrm{tma}=\right.$ trimesate, bpy $=4,4^{\prime}$ bipyridine, $\mathrm{tp}=$ terephthalate). New J. Chem. 27(6), 914-918.

Dai, J. C., Wu, X. T., Fu, Z. Y., Hu, S. M., Du, W. X., Cui, C. P., Wu, L. M., Zhang, H. H. and Sun, R. Q. (2002). A novel ribbon-candy-like supramolecular architecture of cadmium(II)terephthalate polymer with giant rhombic channels: twofold interpenetration of the 3D 8210-a net. Chemical Communications. 2(1): 12-13.

De Lill, D. T., De Bettencourt-Dias, A. and Cahill, C. L. (2007). Exploring lanthanide luminescence in metalorganic frameworks: synthesis, structure, and guest-sensitized luminescence of a mixed europium/terbium-adipate frame- 
work and a terbium-adipate framework. Inorganic Chemistry. 46(10): 3960-3965.

Doty, F. P., Bauer, C. A., Skulan, A. J., Grant, P. G. and Allendorf, M. D. (2009). Scintillating metal-organic frameworks: A new class of radiation detection materials. Advanced Materials. 21(1): 95-101.

Du, J. L., Hu, T. L., Li, J. R., Zhang, S. M. and $\mathrm{Bu}$, X. H. (2008). Metal coordination architectures of 2,3-bis(triazol-1ylmethyl)quinoxaline: Effect of metal ion and counterion on complex structures. European Journal of Inorganic Chemistry. 7: 1059-1066.

Fan, J., Zhu, H. F., Okamura, T. A., Sun, W. Y., Tang, W. X. and Ueyama, N. (2003). Three-dimensional photoluminescent pillared metalorganic framework with $4.8^{2}$ topological channels obtained from the assembly of cadmium(II) acetate and trimellitic salt. New Journal of Chemistry. 27(10): 1409-1411.

Feng, W., Xu, Y., Zhou, G., Zhang, C. and Zheng, $X$. (2007). Hydrothermal synthesis, crystal structure and strong blue fluorescence of a novel 3D coordination polymer containing copper and zinc centers linked by isonicotinic acid ligands. Inorganic Chemistry Communications. 10(1): 49-52.

Frisch, M. and Cahill, C. L. (2005). Syntheses, structures and fluorescent properties of two novel coordination polymers in the U-Cu-H3pdc system. Dalton Transactions. 8: 1518-1523.

Gunning, N. S. and Cahill, C. L. (2005). Novel coordination polymers and structural systematics in the hydrothermal $M, M^{\prime}$ trans-3(-3pyridyl)acrylic acid system. Dalton Transactions. 3(16): 2788-2792.

Hu, Z., Deibert, B. J. and Li, J. (2014).
Luminescent metal-organic frameworks for chemical sensing and explosive detection. Chemical Society Reviews. 43(16): 5815-5840.

Huang, F. and Anslyn, E. V. (2015). Introduction: Supramolecular Chemistry. Chemical Reviews. 115(15): 6999.

Huang, Y., Ding, B., Song, H., Zhao, B., Ren, P., Cheng, P., Wang, H., Liao, D.-Z. and Yan, S. P. (2006). A novel 3D porous metal-organic framework based on trinuclear cadmium clusters as a promising luminescent material exhibiting tunable emissions between UV and visible wavelengths. Chem. Commun. 366(47): 4906-4908.

Janiak, C. (2003). Engineering coordination polymers towards applications. Journal of the Chemical Society. Dalton Transactions. 3(14): 27812804.

Lee, E. Y., Jang, S. Y. and Suh, M. P. (2005). Multifunctionality and Crystal Dynamics of a Highly Stable, Porous Metal-Organic Framework $\left[\mathrm{Zn}_{4} \mathrm{O}(\mathrm{NTB})_{2}\right]$. Journal of the American Chemical Society. 127(17): 6374-6381.

Li, M. X., Miao, Z. X., Shao, M., Liang, S. W. and Zhu, S. R. (2008). Metal-organic frameworks constructed from 2,4,6tris(4-pyridyl)-1,3,5- triazine. Inorganic Chemistry. 47(11): 44814489.

Lill, D. T. De, Gunning, N. S., Cahill, C. L. and George, T. (2004). Toward Templated Metal - Organic Frameworks: Synthesis, Structures, Thermal Properties, and Luminescence of Three Novel Lanthanide - Adipate Frameworks. Inorganic Chemistry. 44(2): 258-266.

Limpouchová, Z. and Procházka, K. (2016). Fluorescence Studies of Polymer Containing Systems (K. Procházka 
(ed.). Vol. 16.

Lu, W. G., Jiang, L., Feng, X. L. and Lu, T. B. (2006). Three 3D coordination polymers constructed by $\mathrm{Cd}(\mathrm{II})$ and Zn(II) with imidazole-4,5-dicarboxylate and 4,4'-bipyridyl building blocks. Crystal Growth and Design. 6(2): 564-571.

McManus, G. J., Perry IV, J. J., Perry, M., Wagner, B. D. and Zaworotko, M. J. (2007). Exciplex fluorescence as a diagnostic probe of structure in coordination polymers of $\mathrm{Zn}^{2+}$ and 4,4'-bipyridine containing intercalated pyrene and enclathrated aromatic solvent guests. Journal of the American Chemical Society. 129(29): 9094-9101.

Orellana, G. (2006). FLUORESCENCE-BASED SENSORS. In Optical Chemical Sensors. Pp. 99-116.

Ouyang, X. M., Li, Z. W., Okamura, T., Li, Y. Z., Sun, W. Y., Tang, W. X. and Ueyama, N. (2004). Construction of metal-organic frameworks through coordination and hydrogen bonding interactions: Syntheses, structures and photoluminescent properties of metal complexes with macrocyclic ligand. Journal of Solid State Chemistry. 177(1): 350-360.

Pham, B. T. N., Lund, L. M. and Song, D. (2008). Novel Luminescent MetalOrganic Frameworks $\left[\mathrm{Eu}_{2} \mathrm{~L}_{3}(\mathrm{DMSO})_{2}\right.$ $\left.(\mathrm{MeOH})_{2} \quad\right] \cdot 2 \mathrm{DMSO} \cdot 3 \mathrm{H}_{2} \mathrm{O}$ and $\left[\mathrm{Zn}_{2} \mathrm{~L}_{2}(\mathrm{DMSO})_{2}\right] \cdot 1.6 \mathrm{H}_{2} \mathrm{O} \quad\left(\mathrm{L}=4,4^{\prime}-\right.$ Ethyne-1,2-diyldibenzoate). Inorganic Chemistry. 47(14): 6329-6335.

Pickup, J. C., Hussain, F., Evans, N. D., Rolinski, O. J. and Birch, D. J. S. (2005). Fluorescence-based glucose sensors. Biosensors and Bioelectronics. 20(12): 2555-2565.

Rao, X., Huang, Q., Yang, X., Cui, Y., Yang, Y., Wu, C., Chen, B., \& Qian, G. (2012). Color tunable and white light emitting
Tb 3+ and Eu 3+ doped lanthanide metal-organic framework materials. Journal of Materials Chemistry. 22(7): 3210-3214.

Reineke, T. M., Eddaoudi, M., Fehr, M., Kelley, D. and Yaghi, O. M. (1999). From Condensed Lanthanide Coordination Solids to Microporous Frameworks Having Accessible Metal Sites. Journal of the American Chemical Society. 121(8): 1651-1657.

Rieter, W. J., Taylor, K. M. L. and Lin, W. (2007). Surface modification and functionalization of nanoscale metalorganic frameworks for controlled release and luminescence sensing. Journal of the American Chemical Society. 129(32): 9852-9853.

Rosen, D. L., Sharpless, C. and McGown, L. B. (1997). Bacterial Spore Detection and Determination by Use of Terbium Dipicolinate Photoluminescence. Analytical Chemistry. 69(6): 10821085.

Rowsell, J. L. C. and Yaghi, O. M. (2004). Metal-organic frameworks: A new class of porous materials. Microporous and Mesoporous Materials. 73(1-2): 3-14.

Sengupta, S., Pal, N. and Bhattacharyya, A. (2021). Synthesis of Coumarin Based Chemo-Sensors for the Detection of $\mathrm{CN}^{-}$Ions. International Journal of Experimental Research and Review. 25: 18-33.

Tachikawa, T., Choi, J. R., Fujitsuka, M. and Majima, T. (2008). Photoinduced charge-transfer processes on MOF-5 nanoparticles: Elucidating differences between metal-organic frameworks and semiconductor metal oxides. Journal of Physical Chemistry C. 112(36): 14090-14101.

Wang, X., Bi, Y., Lin, H. and Liu, G. (2007). Three Novel Cd(II) Metal-Organic Frameworks Constructed from Mixed 
Ligands of Dipyrido $\left[3,2-d: 2^{\prime}, 3^{\prime}-f\right.$ ]quinoxaline and Benzenedicarboxylate: From a 1-D Ribbon, 2-D Layered Network, to a 3-D Architecture. Crystal Growth \& Design. 7(6): 1086-1091.

Wolfbeis, O. S. (2005). Materials for fluorescence-based optical chemical sensors. Journal of Materials Chemistry. 15(27-28): 2657-2669.

Yang, E. C., Li, J., Ding, B., Liang, Q. Q., Wang, X. G. and Zhao, X. J. (2008). An eight-connected 3D lead(II) metalorganic framework with octanuclear lead(II) as a secondary building unit: Synthesis, characterization and luminescent property. Cryst. Eng. Comm. 10(2): 158-161.
Yin, P.X., Zhang, J., Li, Z. J., Qin, Y. Y., Cheng, J. K., Zhang, L., Lin, Q.P. and Yao, Y. G. (2009). Supramolecular Isomerism and Various Chain/Layer Substructures in Silver(I) Compounds: Syntheses, Structures, and Luminescent Properties. Crystal Growth \& Design. 9(11): 4884-4896.

Zhou, C. S. and Zhang, G. C. (2008). Crystal structure of poly-aqua[(pyridine-2,6dicarboxylic acid N-oxide) (4,4'bipyridine)nickel(II)] dihydrate, ( $\mathrm{Ni}\left(\mathrm{C}_{7} \mathrm{H}_{3} \mathrm{NO}_{5}\right)$ $\left.\left(\mathrm{C}_{10} \mathrm{~N}_{2} \mathrm{H}_{8}\right)_{0.5}\left(\mathrm{H}_{2} \mathrm{O}\right)\right) \cdot 2 \mathrm{H}_{2} \mathrm{O}$. Zeitschrift Für Kristallographie - New Crystal Structures. 223(2): 175-176. 